\title{
STUDY CROSS SECTIONAL : DUKUNGAN KELUARGA DENGAN KEPATUHAN HEMODIALISA PADA PASIEN GAGAL GINJAL KRONIS
}

\section{Chauverim Jeremi Gotlieb Paath ${ }^{1}$, Gresty Masi ${ }^{2}$, Franly Onibala ${ }^{3}$}

1. Mahasiswa Program Studi Ilmu Keperawatan, Fakultas Kedokteran, Universitas Sam Ratulangi, Indonesia

2. Program Studi Ilmu Keperawatan, Fakultas Kedokteran, Universitas Sam Ratulangi, Indonesia

3. Akademi Keperawatan Matuari Waya, Manado, Sulawesi Utara, Indonesia

4. Email : chauverim.paath@gmail.com

\begin{abstract}
Chronic Kidney Disease is progressive and irreversible kidney dysfunction where the body fails to maintain metabolim and fluid and electrolyte balance. Hemodialysis therapy is one of managements of CKD. Disobedience may causing failure of the therapy so it can increase mortality and morbidity numbers. Purpose: The purpose of this research is to find out the correlation beetween family support and hemodialysis adherence of patients with CKD. Method: this study used descriptive Analytic with Cross Sectional Study approach. This study involved 50 respondents with Chronic Kidney Disease using the total sampling technique. Data collection was done through the questionnaire about family's support and hemodialysis therapy adherence of patient of CKD. The result of this study showed a significant correlation with $p$ value $=0,000(\alpha<0,05)$. Conclusion: There is a significant correlation beetween family support and hemodialysis therapy adherence of patients with CKD. Further studies are suggested to do other research about specification of family's support with the example instrumental support.
\end{abstract}

Key Words: Chronic Kidney Disease, Family Support, Hemodialysis Therapy

Adherence.

Abstrak: Gagal ginjal kronis merupakan gangguan fungsi ginjal yang progresif dan ireversibel dimana tubuh gagal untuk mempertahankan metabolisme dan keseimbangan cairan dan elektrolit. Terapi hemodialisa adalah salah satu penanganan gagal ginjal kronis. Ketidakpatuhan dapat menyebabkan kegagalan terapi sehingga meningkatkan angka mortalitas dan morbiditas. Dukungan keluarga merupakan salah satu faktor penting dalam meningkatkan kepatuhan terapi. Tujuan: ujuan penelitian ini untuk mengetahui hubungan dukungan keluarga dengan kepatuhan terapi hemodialisa pada pasien GGK. Desain Penelitian: Penelitian ini menggunakan Deskriptif Analitik dengan pendekatan cross-sectional Study. penelitian ini menggunakan 50 responden dengan menggunakan teknik total sampling. Pengumpulan data dilakukan menggunakan kuesioner tentang dukungan keluarga dan kepatuhan menjalani terapi hemodialysis pada pasien CKD. Hasil dari penelitian ini menunjukan hubungan yang signifikan dengan nilai $\mathrm{p}=0,000$ yang berarti nilai $\mathrm{p}<\alpha=0,05$. Kesimpulan: Dapat disimpulkan bahwa ada hubungan yang bermakna antara dukungan keluarga dengan kepatuhan hemodialisa pada pasien GGK. Bagi peneliti selanjutnya disarankan untuk melakukan penelitian tentang dukungan keluarga yang lebih spesifik contohnya dukungan instrumental.

Kata Kunci: Gagal Ginjal Kronis, Dukungan Keluarga, Kepatuhan Hemodialisa 


\section{PENDAHULUAN}

Gagal ginjal kronik merupakan gangguan fungsi ginjal yang progresif dan ireversibel dimana tubuh gagal untuk mempertahankan metabolisme dan keseimbangan cairan dan eleketrolit, menyebabkan retensi urin dan sampah nitrogen lain dalam darah. (Muttaqin \& Kumala, 2011 dalam Erikka M. Panjaitan, 2014)

Prevalensi gagal ginjal kronik menurut World Heath Organization (2018) merupakan salah satu masalah kesehatan utama di dunia, secara global sekitar 1 dari 10 populasi dunia teridentifikasi penyakit ginjal kronis (Wilyanarti, 2019). Hasil Riskesdas (2013) mengatakan bahwa jumlah penderita di Indonesia sendiri mencapai 3,8 \% dari jumlah penduduk Indonesia, hanya 19,3\% dari pasien gagal ginjal kronis tersebut yang menjalani terapi dialisis. Sulawesi Utara menjadi provinsi dengan prevalensi terbanyak ketiga di bawah provinsi Kalimantan Utara dan Maluku Utara (Riskesdas, 2018).

Bagi penderita gagal ginjal kronik, hemodialisa akan mencegah kematian. Hemodaliss yang dijalani oleh pasien dapat mempertahankan kelangsungan hidup sekaligus merubah pola hidup pasien (Mailani, 2015).

Menurut Sunarni (2009), dukungan keluarga merupakan salah satu faktor ketidakpatuhan dalam perawatan hemodialisa. Ketidakpatuhan dapat menyebabkan kegagalan terapi sehingga meningkatkan angka mortalitas dan morbiditas (Fauziah, 2016). Jika ketidakpatuhan terjadi maka akan sangat merugikan diri pasien, mulai dari jadwal terapi yang akan berubah menjadi lebih sering yang diakibatkan karena komplikasi yang ditimbulkan oleh edema, juga akan memperberat biaya terapi dari biasanya (Almatsier, 2008). Sehingga kepatuhan menjadi salah satu permasalahan pada pasien hemodialisa yang mengalami penyakit ginjal kronis, karena dapat berdampak pada perawatan pasien, termasuk konsistensi kunjungan, pengobatan serta diit dan cairan (Syamsah, 2011).

\section{METODE PENELITIAN}

Desain penelitian ini menggunakan metode deskriptif analitik dengan menggunakan rancangan cross sectional study (studi potong lintang). Penelitian ini dilaksanakan pada bulan Oktober -November 2019 di ruang Hemodialisa RSU GMIM Bethesda Tomohon. Populasi yang digunakan dalam penelitian ini adalah pasien yang menjalani hemodialisa di ruang hemodialisa RSU GMIM Bethesda Tomohon yang berjumlah 50 orang dan Sampel diambil dengan menggunakan total sampling. Instrumen pada penelitian ini menggunakan lembar kuesioner yang terdiri dari pernyataan yang berkaitan dengan dukungan keluarga dan kepatuhan hemodialisa pada pasien gagal ginjal kronik. Dalam pengumpulan data untuk dukungan keluarga, peneliti menggunakan kuesioner yang pernah digunakan dari penelitian sebelumnya oleh Syamsiah (2011). Yang telah diuji validitas dan reliabilitasnya. Berdasarkan hasil uji validitas didaptkan $r$ hasil dari semua pernyataan lebih besar dari $\mathrm{r}$ tabel, sehingga dapat dikatakan seluruh pernyataan tersebut dinyatakan valid. Adapun untuk uji reliabilitas, didaptkan $r$ alpha lebih besar dari $r$ tabel $(0,907>0,423)$, maka seluruh pernyataan dinyatakan reliabel. 


\section{HASIL}

\section{A. Analisis Univariat}

Tabel 1 : Karakteristik Responden berdasarkan data demografi

\begin{tabular}{|c|c|c|}
\hline Kategori & Frekuensi & $\%$ \\
\hline $\begin{array}{l}\text { Usia: } \\
\leq 50 \text { tahun } \\
>50 \text { tahun } \\
\text { Total }\end{array}$ & $\begin{array}{l}14 \\
36 \\
50\end{array}$ & $\begin{array}{c}28 \% \\
72 \% \\
100 \%\end{array}$ \\
\hline $\begin{array}{l}\text { Jenis Kelamin: } \\
\text { Perempuan } \\
\text { Laki-laki } \\
\text { Total } \\
\end{array}$ & $\begin{array}{l}26 \\
24 \\
50 \\
\end{array}$ & $\begin{array}{c}52 \% \\
48 \% \\
100 \% \\
\end{array}$ \\
\hline $\begin{array}{l}\text { Pendidikan: } \\
\text { SD } \\
\text { SMP } \\
\text { SMA } \\
\text { Perguruan Tinggi } \\
\text { Lain-lain } \\
\text { Total }\end{array}$ & $\begin{array}{c}12 \\
3 \\
22 \\
10 \\
3 \\
50\end{array}$ & $\begin{array}{c}24 \% \\
6 \% \\
44 \% \\
20 \% \\
6 \% \\
100 \%\end{array}$ \\
\hline
\end{tabular}

Sumber : Data Primer 2019

Berdasarkan data diatas didapati paling banyak penderita CKD berjenis kelamin perempuan dengan frekuensi $52 \%$ sebagian besar responden berusia diatas 50 tahun dengan frekuensi $72 \%$, dan dengan tingkat pendidikan terbanyak lulusan SMA dengan frekuensi $44 \%$.

\section{B. Analisa Bivariat}

Tabel 2 : Dukungan Keluarga dengan Kepatuhan Hemodialisa Pada Pasien Gagal Ginjal Kronik

\begin{tabular}{|c|c|c|c|c|c|c|}
\hline \multirow{2}{*}{$\begin{array}{c}\text { Dukungan } \\
\text { Keluarga }\end{array}$} & \multicolumn{4}{|c|}{$\begin{array}{c}\text { Kepatuhan } \\
\text { Terapi Hemodialisa }\end{array}$} & \multirow[t]{2}{*}{ Total } & \multirow[t]{2}{*}{ P-value } \\
\hline & Patuh & $\%$ & $\begin{array}{l}\text { Tidak } \\
\text { Patuh }\end{array}$ & $\%$ & & \\
\hline Kurang & 1 & $2.2 \%$ & 4 & $100 \%$ & 5 & 0.000 \\
\hline Baik & 45 & $97.8 \%$ & 0 & $0 \%$ & 45 & \\
\hline Total & 46 & $100 \%$ & 4 & $100 \%$ & 50 & \\
\hline
\end{tabular}

Sumber : Data Primer 2019

Berdasarkan data diatas menunjukkan bahwa 45 responden mendapatkan dukungan keluarga baik dan patuh menjalani terapi hemodialisa, tidak ada responden yang mendapat dukungan keluarga baik dan tidak patuh, 1 responden mendapatkan dukungan keluaga yang kurang dan patuh, dan 4 responden mendapatkan dukungan keluarga yang kurang dan tidak patuh. 
Hasil uji statistik didapatkan bahwa nilai $p$-value $(0.000) \quad<\mathrm{a} \quad 0,05$. dengan demikian, $\mathrm{H}_{\mathrm{o}}$ ditolak yang berarti ada hubungan yang signifikan antara dukungan keluarga dengan kepatuhan hemodialisa pasien GGK.

\section{PEMBAHASAN}

\section{A. Karakteristik responden}

Hasil uji berdasarkan usia, dari 50 responden diperoleh paling banyak responden berusia $>50$ tahun sebesar 36 orang $(72 \%)$. Hasil ini sejalan dengan penelitian Utami (2015) di RSUD Arifin Achmad Pekanbaru dengan sampel sebanyak 105 responden menyimpulkan bahwa responden atau pasien gagal ginjal sebagian besar berusia di atas 50 tahun, sebesar 68,6 \%. Data Kemenkes didapati bahwa pada tahun 2016, usia pasien GGK yang menjalani hemodialisis paling berada di atas 50 tahun. Gagal ginjal terjadi pada semua rentang usia dan mempunyai penyebab yang berbeda-beda (Groer, 2001). Sesuai denga teori Smeltzer \& Bare (2002) bahwa sesudah usia 40 tahun akan terjadi penurunan laju filtrasi glomerulus (LFG) secara progresif hingga usia 70 tahun, fungsi tubulus termasuk kemampuan reabsorpsi dan pemekatan juga berkurang. Hal tersebut menyebabkan terjadinya penyakit gagal ginjal. Itulah yang menyebabkan banyak pasien teridentifikasi menderita gagal ginjal saat mulai memasuki usia 50 tahun. (Anita, 2015)

Hasil uji berdasarkan jenis kelamin, diperoleh data perempuan sebesar 26 responden $(52 \%)$ dan laki-laki 24 responden $(48 \%)$. Hasil ini menunjukkan bahwa prevalensi penderita penyakit GGK hampir seimbang. Hasil ini sejalan dengan penelitian Anita (2015) di RS PKU Muhammaditah Gamping Yoyakarta dengan sampel sebanyak 60 responden menyimpulkan bahwa sebagian responden berjenis kelamin perempuan sebesar $55 \%$. Data ini didukung data Kemenkes, yaitu prevalensi penderita penyakit ginjal kronik hampir berimbang dimana prevalensi penderita GGK berjenis kelamin perempuan sebesar 55\% dan laki-laki sebesar $45 \%$ (Kemenkes RI, 2018).

Berdasarkan pendidikan, diperoleh hasil dari 50 responden jumlah responden paling banyak mempunyai jenjang pendidikan SMA yaitu 22 orang (44\%). Hasil penelitian ini sejalan dengan penelitian Nita Syamsiah (2011) di RSAU Dr. Esnawan Antariksa Halim Perdana Kusuma Jakarta Selatan denga besar sampel 158 responden menyimpulkan bahwa lebih banyak responden berlatar belakang pendidikan menengah (SMA) yaitu berjumlah 78 orang $(49,7 \%)$. Menurut Notoatmodjo (2003) pengetahuan merupakan domain yang sangat penting dalam membentuk tindakan seseorang. Tindakan seseorang. Tindakan yang didasari dengan pengetahuan akan lebih baik daripada tindakan yang tidak didasari oleh pengetahuan. Seseorang yang memiliki tingkat pendidikan tinggi seharusnya memiliki perilaku yang lebih baik dalam menjaga kesehatan, termasuk dalam mematuhi terapi hemodialisis (Anita, 2015)

\section{B. Analisa Univariat}

Hasil penelitian menunjukkan bahwa dukungan keluarga berada dalam kategori baik, yaitu sebesar $90 \%$. Dukungan keluarga menurut Murniasih (2007) adalah sikap, tindakan penerimaan keluarga terhadap anggota keluarganya. Anggota keluarga dipandang sebagai bagian yang tak terpisahkan dalam lingkungan keluarga. 
Anggota keluarga memandang bahwa orang yang bersifat mendukung selalu siap memberikan pertolongan dan bantuan jika diperlukan. Dukungan keluarga yang diberikan berupa membantu mencari informasi tentang bagaimana proses terapi hemodialisa, serta manfaat menjalani terapi hemodialisa. Keluarga saling berkomunikasi dengan pasien tentang kesulitan yang dialaminya selama menjalani terapi. Keluarga memberikan perhatian, semangat, dan menghibur agar pasien terus menjalani terapi hemodialisa. Keluarga juga dalam tugasnya untuk merawat anggota keluarga yang sakit berperan dalam membiayai proses perawatan, dan menyediakan fasilitas-fasilitas yang dibutuhkan pasien.

Kepatuhan pasien dalam menjalankan terapi HD dalam penelitian ini didapati sangatlah baik, hal ini dikarenakan adanya dukungan keluarga sangat membantu responden dalam menjalani setiap proses terapi. Bisaroh (2013) menyampaikan hasil penelitian serupa bahwa upaya keluarga untuk meningkatkan kepatuhan dalam melakukan terapi hemodialisa dapat dilakukan bermacam-macam, yaitu dengan cara membantu membuat jadwal sederhana terapi HD sehingga memudahkan pasien mengingat untuk melakukan terapi, selain itu membantu transportasi pasien ke tempat terapi HD agar pasien tdak mengalami kesulitan dalam menjalankan terapi.

\section{Analisa Bivariat}

Hasil penelitian menunjukkan bahwa 45 responden mendapatkan dukungan keluarga yang baik dan patuh menjalani terapi hemodialisa. Hasil uji menggunakan uji Chi-Square pada penelitian ini diproleh hasil yang signifikan $(\mathrm{p}=0.000)$ yang berarti $\mathrm{p}$-value $<0,05$ menunjukkan bahwa ada hubungan antara dukungan keluarga dan kepatuhan hemodalisa pasien GGK.

Padilla (2012) mengatakan bahwa salah satu tugas keluarga adalah untuk melakukan perawatan atau pemeliharaan kesehatan, yaitu untuk mempetahankan keadaan kesehatan anggota keluarga agar tetap memiliki produktifitas tinggi. Jika pasien tidak mendapatka dukungan keluarga yang baik maka pasien akan merasa tertekan bahwa tidak ada yang memperhatikan kondisinya dan hal ini dapat mempengaruhi kesehatan tubuhnya. Jadi, keluarga diharapkan dapat memenuhi semua kebutuhan kesehatan guna meningkatkan kesehatan guna meningkatkan kualitas hidup dan mencegah penyakit.

Penelitian yang dilakukan oleh Kamaludin (2009) di RSUD Prof. dr. Margono Soekardjo Purwokerto menunjukkan bahwa semakin baik dukungan keluarga, maka semakin tinggi pula kepatuhan seseorang khususnya pasien gagal ginjal kronis dalam menjalankan terapi hemodialisis. Dijelaskan bahwa kepatuhan dalam menjalankan terapi HD dipengaruhi oleh besarnya dukungan keluarga yang diterima, selain itu keluarga selalu mengingatkan jadwal terapi HD pada pasien. Kepatuhan pasien juga berasal dari dukungan biaya oleh keluarga sehingga pasien tidak khawatir akan pengobatannya.

Hasil penelitian dan teori di atas sejalan dengan hasil peneltian yang diperoleh peneliti, dimana hasil penelitian dan teori tersebut semakin menguatkan pendapat peneliti bahwa terdapat hubungan antara dukungan keluarga dan kepatuhan hemodialisa pada pasien GGK. 


\section{SIMPULAN}

Berdasarkan hasil analisis didapatkan sebagian besar responden mendapatkan dukungan keluarga pada pasien gagal ginjal kronik yang baik dan patuh dalam menjalani terapi hemodialisa dan dapat disimpulkan bahwa terdapat hubungan yang signifikan antara Dukungan Keluarga Dengan Kepatuhan Hemodialisa Pada Pasien Gagal Ginjal Kronis di RSU GMIM Bethesda Tomohon. Dan diharapkan bagi tenaga keperawatan agar dapat memberikan penyuluhan kesehatan secara berkesinambungan tentang penyakit gagal ginjal kronik dan terapi hemodialisa, dan bagi peneliti selanjutnya disarankan untuk melakukan penelitian tentang dukungan keluarga yang lebih spesifik contohnya dukungan instrumental.

\section{DAFTAR PUSTAKA}

Almatsier, Sunita. (2008). Penuntun Diet. Jakarta: Gramedia Pustaka Utama.

Amri Fauziah. (2015). Hubungan Antara Kepatuhan Menjalani Terapi Hemodialisa Dengan Kualitas Hidup Pasien Gagal Ginjal Kronik Di Ruang Hemodialisa RSUD Dr. Soedirman Kebumen.

Diyah C.A., Dwi Novitasari. (2015). Kepatuhan Pembatasan Asupan Cairan Terhadap Lama Menjalani Hemodialisa di RSU PKU Muhammadiyah Gamping Yogyakarta.

Fitri Maliani. (2015). Kualitas Hidup Pasien Penyakit Ginjal Kronik
Yang Menjalani Hemodialisis: Systematic Review.

Groer, M. W. (2001). Advanced Pathophysiology, Application to Clinical Practice. Philadelphia: Lippincot.

Kamaludin, R .(2009). Analisis Faktor-Faktor Yang

Mempengaruhi Kepatuhan Asupan Cairan Pada Pasien Gagal Ginjal Kronik Dengan Hemodialisa Di RSUD Prof. Dr. Margono Soekardjo Purwekerto.

Kemenkes RI. (2018). Air Bagi Kesehatan: Upaya Peningkatan Promotif Preventif Kesehatan Ginjal Di Indonesia.

Murniasih. (2007). Hubungan Dukungan Keluarga Dengan Tingkat Kecemasan Akibat Hospitalisasi Pada Anak.

Muttaqin, Arif \& Sari, Kumala. (2011). Asuhan Keperawatan Gangguan Sistem Perkemihan. Jakarta: Salemba Medika.

Padilla. (2012). Buku Ajar Keperawatan Keluarga. Yogyakarta: Nuha Medika.

Riset Kesehatan Dasar. (2018). Badan Penelitian dan Pengembangan Kesehatan Kementrian Kesehatan $R I$.

Syamsiah, N. (2011). Faktor-faktor yang Berhubungan Dengan Kepatuhan Pasien CKD Menjalani Hemodialisa. 
World Health Organization. (2018). The

World Health Organization;

Quality of Life. 